\title{
Factors contributing to hospitalization costs for patients with COPD in China: a retrospective analysis of medical record data
}

This article was published in the following Dove Press journal: International Journal of COPD

\author{
Meng $\mathrm{Li}^{\prime}$ \\ Fengyan Wang ${ }^{2}$ \\ Rongchang Chen ${ }^{2}$ \\ Zhenyu Liang ${ }^{2}$ \\ Yumin Zhou ${ }^{2}$ \\ Yuqiong Yang ${ }^{2}$ \\ Shengqi Chen' \\ Carolina Oi Lam Ung' \\ $\mathrm{HaO} \mathrm{Hu}^{\prime}$ \\ 'State Key Laboratory of Quality \\ Research in Chinese Medicine, \\ Institute of Chinese Medical Sciences, \\ University of Macau, Macao; ${ }^{2}$ State \\ Key Laboratory of Respiratory \\ Disease, National Clinical Research \\ Center for Respiratory Disease, \\ Guangzhou Institute of Respiratory \\ Health, First Affiliated Hospital \\ of Guangzhou Medical University, \\ Guangzhou China
}

Correspondence: Carolina Oi Lam Ung; $\mathrm{HaO} \mathrm{Hu}$

State Key Laboratory of Quality Research in Chinese Medicine, Institute of Chinese Medical Sciences, Research building N222057, University of Macau, Avenida da Universidade, Macao, China

Tel +853 88228538

Email carolinaung@umac.mo; haohu@umac.mo
Purpose: Hospitalization brings considerable economic pressure on COPD patients in China. A clear understanding of hospitalization costs for patients with COPD is warranted to improve treatment strategies and to control costs. Currently, investigation on factors contributing to hospitalization costs for patients with COPD in China is limited. This study aimed to measure the hospitalization costs of COPD and to determine the contributing factors.

Patients and methods: Medical record data from the First Affiliated Hospital of Guangzhou Medical University from January 2016 to December 2016 were used for a retrospective analysis. Patients who were hospitalized with a diagnosis of COPD were included. Patient characteristics, medical treatment, and hospitalization costs were analyzed by descriptive statistics and multivariable regression.

Results: Among the 1,943 patients included in this study, $87.85 \%$ patients were male; the mean (SD) age was 71.15 (9.79) years; $94.49 \%$ patients had comorbidities; and $82.30 \%$ patients had health insurance. Regarding medical treatment, the mean (SD) length of stay was 9.38 (7.65) days; $11.12 \%$ patients underwent surgery; $87.91 \%$ used antibiotics; and $4.53 \%$ underwent emergency treatment. For hospitalization costs, the mean (SD) of the total costs per COPD patient per admission was 24,372.75 (44,173.87) CNY $(3,669.33$ [6,650.38] USD), in which Western medicine fee was the biggest contributor $(45.53 \%)$ followed by diagnosis fee $(27.00 \%)$ and comprehensive medical fee $(12.04 \%)$. Regression found that reimbursement $(-0.032 ; 95 \%$ CI -0.046 to 0.007$)$, length of stay $(0.738 ; 95 \%$ CI $0.832-0.892)$, comorbidity (0.044; $95 \%$ CI $0.029-0.093)$, surgery $(0.145$; $95 \%$ CI $0.120-0.170)$, antibiotic use $(0.086$; $95 \%$ CI $0.060-0.107)$, and emergency treatment $(0.121 ; 95 \%$ CI $0.147-0.219)$ were significantly $(P<0.01)$ associated with total hospitalization costs.

Conclusion: To control hospitalization costs for COPD patients in China, the significance of comorbidity, length of stay, antibiotic use, surgery, and emergency treatment suggests the importance of controlling the COPD progression and following clinical guidelines for inpatients. Interventions such as examination of pulmonary function for early detection, quality control of medical treatment, and patient education warrant further investigation.

Keywords: COPD, economic burden, hospitalization costs, medical cost, multivariate regression

\section{Introduction}

COPD is a common chronic respiratory disease with high mortality and morbidity. It is estimated that COPD will be the third leading cause of death in the world by $2030 .{ }^{1}$ Globally, COPD has caused huge burden on health systems. ${ }^{2}$ As disease progresses, patients are more likely to be hospitalized for the necessary treatment. The treatment costs of COPD patients have a strong correlation with the disease severity, ${ }^{3}$ in which 
hospitalization costs account for most of the direct treatment costs. ${ }^{4}$ A study in the US reported that the hospitalization costs significantly drove the total health care costs in COPD patients who were commercially insured. ${ }^{5}$ In Taiwan, the hospitalization costs for COPD patients accounted for $74 \%-95 \%$ of their total health care costs. ${ }^{6}$

There are multiple factors contributing to the high hospitalization costs for COPD patients including age, use of domiciliary oxygen, presence of comorbidity, history of lung infection, and length of stay. ${ }^{7,8}$ Some factors are related to patient's demographic characteristics which may not be easily controlled for cost-containment purposes. Other factors are related to treatment strategies adopted by the hospital where patients were admitted which could play a major role in driving hospitalization costs. To explore measures that can help reduce the treatment costs of COPD patients, it is necessary to have a good understanding of the factors that can contribute to the hospitalization costs in different health systems.

China has one of the largest COPD populations in the world. According to "The 2015 Report on Chinese Nutrition and Chronic Disease", there were more than 43 million COPD patients in China, and the prevalence of COPD varied from $5 \%$ to $13 \%$ across different regions of the country. For most regions, the prevalence was higher than the WHO modelestimated prevalence for Chinese $(6.7 \%){ }^{9}$ A recent large epidemic study of COPD in China found that the COPD prevalence over the age of 20 years in China was $8.6 \%$, and the prevalence of people over the age of 40 years was as high as $13.7 \% .{ }^{10}$ A cross-sectional study from four China cities found that the mean annual direct medical costs per COPD patient were $11,968( \pm 22,422) \mathrm{CNY}(1,853[ \pm 3,472] \mathrm{USD})$ in $2011 .^{11}$ According to a published Chinese experts' consensus in 2013, the medical costs of COPD patients during hospitalization were expected to increase significantly. ${ }^{12}$ Another study found that a significant upward trend of the mean cost per stay for COPD patients increased from 5,168 CNY (637.92 USD) in 2005 to 9,772 CNY $\left(1,568.94\right.$ USD) in $2015 .{ }^{13}$ Hospitalization brought considerable economic pressure on COPD patients and the overall health system in China. ${ }^{14} \mathrm{~A}$ clear understanding of hospitalization costs for COPD patients is warranted to improve treatment strategies and to control costs. However, investigation on factors contributing to hospitalization costs for COPD patients in China is limited.

Thus, the objective of this study was to measure the hospitalization costs for COPD patients and to determine the contributing factors. The findings are expected to provide evidence for designing health care service and health policy which benefit COPD patients under medical cost pressure.

\section{Patients and methods}

\section{Data collection}

A retrospective study was performed using data from the First Affiliated Hospital of Guangzhou Medical University. The hospital was chosen for this study because it is a leading institution for respiratory medicine in China. Its respiratory department, which is also known as the Guangzhou Institute of Respiratory Health, was founded in 1979, where it is the earliest research institute for respiratory disease in China. The institute was approved by the Chinese Central Government as the State Key Laboratory of Respiratory Disease in 2007 and the National Clinical Research Center for Respiratory Disease in 2015. Due to its outstanding clinical and research capability in respiratory disease in China, this hospital receives a large number of COPD patients from around the country who seek high-standard treatment.

The study was reviewed and approved by the ethics committee of the First Affiliated Hospital of Guangzhou Medical University (no 201753). This study did not investigate privacy issues involving patient names, ID numbers, home addresses, phone numbers, etc. Therefore, patient consent to review their medical records was not required by the ethics committee of the First Affiliated Hospital of Guangzhou Medical University. All investigators prefer strict confidentiality of patient data.

All the data were extracted from the Neusoft Hospital Information Management System of the First Affiliated Hospital of Guangzhou Medical University. Considering that the financial operation of public hospital in China is annually established to meet the fiscal requirements of government, hospitalized COPD patients who were discharged during the period between January 1, 2016, and December 31, 2016, were chosen. Two inclusion criteria were applied. The first criterion was that patients were hospitalized with main diagnosis as COPD or acute exacerbations of COPD (AECOPD), where the corresponding ICD-10 codes in the dataset included J44.100, J44.800, and J44.900. The second criterion was that patients were hospitalized with main diagnosis as respiratory failure (J96.900) and the second diagnosis as AECOPD. The second inclusion criterion was set, because these patients were hospitalized for AECOPD-induced respiratory failure. The root cause of their hospitalization was also AECOPD. Respiratory failure was defined as the failure to adequately provide oxygen to cells of the body and to remove excess carbon dioxide from them. Arterial blood gas analysis was required to make the diagnosis in this clinical context. The presence of arterial blood oxygen partial pressure of $<60 \mathrm{mmHg}$ with or without carbon dioxide partial 
pressure of $>50 \mathrm{mmHg}$ on room air at sea level confirmed the presence of respiratory failure. This study used data on hospitalization costs per patient admission.

\section{Measurement}

According to the GOLD and the Chinese Guidelines for the Diagnosis and Treatment of COPD (revised 2013) ${ }^{15,16}$ patient symptoms and medical treatment strategy are two decisive aspects of medical costs of COPD patients. The information extracted for analysis in this study, thus, included patient characteristics, medical treatment received by the patient, and the resultant hospitalization costs.

All the data in the Neusoft Hospital Information Management System were categorized according to the official Standard Electronic Inpatient Medical Record Data Set in China.
For this study, patient characteristic information included gender, age, and ways of reimbursement. In China, the health system did not provide reimbursement for all patients, especially for immigrant patients who left their hometown. Medical treatment information included length of stay, comorbidity, surgery, antibiotic use, and emergency treatment. These treatment factors were chosen according to the GOLD guideline and the Chinese Guidelines for the Diagnosis and Treatment of COPD (revised 2013). The third part of hospitalization cost information covered ten categories giving a total of 21 cost items. A summary of all the measurements is listed in Table 1.

\section{Data analyses}

All the information about patient characteristics, medical treatment, and hospitalization costs was first analyzed

Table I Variables and their measurement in this study

\begin{tabular}{|c|c|}
\hline Variables & \multirow{2}{*}{$\begin{array}{l}\text { Measurement } \\
\text { Male }=0 ; \text { female }=I\end{array}$} \\
\hline I. Gender & \\
\hline 2. Age & Numerically indicate the patient's age \\
\hline 3. Reimbursement & No $=0$; yes $=1$ \\
\hline 4. Length of stay & Numerically indicate the days of stay \\
\hline 5. Comorbidity & No $=0 ;$ yes $=1$ \\
\hline 6. Surgery & No $=0 ;$ yes $=1$ \\
\hline 7. Antibiotic use & No $=0 ;$ yes $=1$ \\
\hline 8. Emergency treatment & No $=0 ;$ yes $=1$ \\
\hline 9. Hospitalization costs & (CNY and USD) \\
\hline \multicolumn{2}{|l|}{9.1 Total cost } \\
\hline 9.2 Comprehensive medical fee & $\begin{array}{l}\text { General medical fee } \\
\text { General treatment operation fee } \\
\text { Nurse fee } \\
\text { Other fees }\end{array}$ \\
\hline 9.3 Diagnosis fee & $\begin{array}{l}\text { Pathological diagnosis fee } \\
\text { Laboratory diagnosis fee } \\
\text { Image diagnosis fee } \\
\text { Clinical diagnosis fee }\end{array}$ \\
\hline 9.4 Treatment fee & $\begin{array}{l}\text { Non-surgery treatment fee } \\
\text { Surgery treatment fee }\end{array}$ \\
\hline 9.5 Rehabilitation fee & Rehabilitation fee \\
\hline 9.6 Traditional Chinese medical treatment ${ }^{\mathrm{a}}$ & Traditional Chinese medical treatment fee \\
\hline 9.7 Western medicine fee ${ }^{b}$ & Western medicine fee (including antibiotics fee) \\
\hline $9.8 \mathrm{TCM}_{\mathrm{fee}}^{\mathrm{c}}$ & $\begin{array}{l}\text { Traditional Chinese patent medicine fee } \\
\text { Traditional Chinese herbal medicine fee }\end{array}$ \\
\hline 9.9 Blood and blood products fee & $\begin{array}{l}\text { Blood fee } \\
\text { Albumin fee } \\
\text { Globulin fee } \\
\text { Examination disposable medical materials fee }\end{array}$ \\
\hline 9.10 Consumable materials fee & $\begin{array}{l}\text { Treatment disposable medical materials fee } \\
\text { Surgery disposable medical materials fee }\end{array}$ \\
\hline
\end{tabular}

\subsection{Other fees}

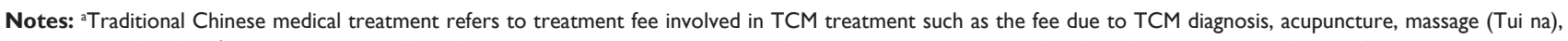
Cupping, and Gua Sha. 'Western medicine fee refers to the pharmaceutical product fee, including antibiotics. 'TCM fee refers to medicine fee in TCM treatment such as Chinese herbal medicine fee, Chinese patent medicine, and Chinese food therapy.

Abbreviation: TCM, traditional Chinese medicine. 
in a descriptive way, using proportions, mean (SD), and median (IQR).

Multivariable regression model was adopted to determine the factors contributing to total hospitalization costs. As the data of total hospitalization costs were not normally distributed, it was log transformed as dependent variable before conducting regression analysis. Eight independent variables were entered into regression model, including gender, age, reimbursement, length of stay, comorbidities, surgery, antibiotic use, and emergency treatment.

Statistical analysis was performed using SPSS 23.0 version (IBM Corporation, Armonk, NY, USA). $P$-value of $<0.05$ was considered to be statistically significant.

\section{Results}

\section{Characteristics of patients}

Among the 1,943 patients included in this study, 1,707 $(87.85 \%)$ patients were male; the mean (SD) age was 71.15 (9.79) years; $1,599(82.30 \%)$ patients had reimbursement for medical payment (Table 2).

\section{Analysis of medical treatment information}

As summarized in Table 2, of the patients included, the mean (SD) length of stay in hospital was 9.38 (7.65) days. A total of $1,836(94.49 \%)$ patients had comorbidities at admission, where the typical comorbidities included hypertension, diabetes, pulmonary infection, pneumonia, and bullae; 1,708 (87.91\%) patients had used antibiotics during hospitalization. In particular, out of 1,943 patients, $216(11.12 \%)$ patients had undergone surgery, where the top four surgeries were fiberoptic bronchoscopy $(n=39)$, thoracentesis $(n=16)$, coronary

Table 2 Characteristics of patients hospitalized for COPD or AECOPD

\begin{tabular}{l|l}
\hline Item & $\mathbf{n}(\%)$ \\
\hline Gender & \\
$\quad$ Male & $1,707(87.85 \%)$ \\
$\quad$ Female & $236(12.15 \%)$ \\
Age, years & $71.15(9.79)$ \\
Median (IQR) & $72.00(64-78)$ \\
Mean (SD) & $71.15(9.79)$ \\
Reimbursement & $1,599(82.30 \%)$ \\
Length of stay, days & \\
$\quad$ Median (IQR) & $7.00(5-11)$ \\
$\quad$ Mean (SD) & $9.38(7.65)$ \\
Comorbidity & $1,836(94.49 \%)$ \\
Surgery & $216(11.12 \%)$ \\
Antibiotic use & $1,708(87.91 \%)$ \\
Emergency treatment & $88(4.53 \%)$ \\
\hline
\end{tabular}

Abbreviation: AECOPD, acute exacerbations of COPD. angiography $(\mathrm{n}=15)$, and closed drainage of pleural cavity $(\mathrm{n}=13)$. In addition, $88(4.53 \%)$ patients received emergency treatment, where "emergency treatment" denoted the treatment under emergency situation and included emergency aid and treatment, and salvage/rescue therapy, such as emergency tracheal intubation and cardiopulmonary resuscitation.

\section{Analysis of hospitalization costs}

For hospitalization costs, the mean (SD) total cost per COPD patient per admission was 24,372.75 (44,173.87) CNY $(3,669.33$ [6,650.38] USD). Western medicine fee consisted of the largest proportion (45.53\%) of the total hospitalization costs, including $17.30 \%$ antibiotics fee. Diagnosis fee accounted for $27.00 \%$ of total hospitalization costs, followed by comprehensive medical fee $(12.04 \%)$, consumable materials fee $(8.81 \%)$, and treatment fee $(5.51 \%)$. Rehabilitation fee accounted for the smallest proportion $(0.08 \%)$. More details are summarized in Table 3.

\section{Regression analysis for total hospitalization costs}

Table 4 summarizes the results of regression analysis on total hospitalization costs. It shows that length of stay (0.738; 95\% CI 0.028-0.031), comorbidity (0.044; 95\% CI $0.056-0.122)$, surgery $(0.145 ; 95 \%$ CI $0.111-0.162)$, antibiotic use $(0.086 ; 95 \%$ CI $0.131-0.178)$, and emergency treatment $(0.121 ; 95 \%$ CI $0.061-0.136)$ were significantly $(P<0.001)$ associated with total hospitalization costs. In addition, total hospitalization costs were significantly $(P=0.007)$ associated with whether patients could get reimbursement for medical payment or not. However, total hospitalization costs were not significantly associated with gender or age.

\section{Discussion}

As hospitalization has a great impact on economic burden for COPD patients and the overall health system, it is necessary to investigate the weight of each contributing factor to hospitalization costs of COPD inpatients. Based on a retrospective analysis of medical record data from a top hospital specialized in respiratory disease in China, this study found that the mean total hospitalization costs per COPD patient per admission was 24,372.75 CNY (3,669 USD) in 2016. A research in the US found that the mean cost of 1,254,703 hospitalizations for AECOPD was 9,545 USD per patient in $2010 .{ }^{17}$ Pasquale et $\mathrm{al}^{18}$ reported that the mean annual COPD-related costs per patient older than 40 years in the USA was 4,528 USD between 2007 and 2009. Although the total hospitalization costs in this study 
Table 3 Analysis of hospitalization cost information (CNY)

\begin{tabular}{|c|c|c|c|}
\hline Cost items & Median (IQR) & Mean (SD) & $\%$ \\
\hline Total cost & I 4,708.75 (10,465.37-22,394.77) & $24,372.75(44,173.87)$ & 100 \\
\hline Western medicine products fee & $5,902.33(3,553.3-10,766.4)$ & I I,093.46 (20,169.24) & 45.53 \\
\hline Antibiotics fee & I,72I.24 (722.70-3,333.20) & $4,227.12(11,182)$ & 17.3 \\
\hline Diagnosis fee & $5,262.80(4,119.80-6,706.00)$ & $6,578.06(7,782.82)$ & 27.00 \\
\hline Pathological diagnosis fee & $0.00(0.00-0.00)$ & $83.82(428.43)$ & 0.34 \\
\hline Laboratory diagnosis fee & $3,3 \mid 7.80(2,545.00-4,146.800)$ & $3,955.30(4,421.35)$ & 16.23 \\
\hline Image diagnosis fee & I,35I.00 (735.00-I,80I.00) & I,533.89 (I,434.08) & 6.29 \\
\hline Clinical diagnosis fee & $387.00(200.00-821.00)$ & I,005.05 $(2,4 \mid 8.00)$ & 4.13 \\
\hline Comprehensive medical fee & $1,932.00(1,284.50-2,872.50)$ & $2,933.76(4,817.66)$ & 12.04 \\
\hline General medical fee & $378.00(276.00-580.00)$ & $634.87(1,292.82)$ & 2.61 \\
\hline General treatment operation fee & I,279.50 (85I.50-I,933.50) & I,69I.76 (I,798.32) & 6.94 \\
\hline Nurse fee & $163.00(102.00-276.00)$ & $553.05(1,981.93)$ & 2.27 \\
\hline Other fees & $48.00(28.00-78.00)$ & $54.05(54.65)$ & 0.22 \\
\hline Consumable materials fee & $794.54(479.90-1,466.18)$ & $2,146.66(9,051.92)$ & 8.81 \\
\hline $\begin{array}{l}\text { Examination disposable medical materials fee } \\
\text { (examination DMMF) }\end{array}$ & $0.00(0.00-29.70)$ & $163.69(1,688.9)$ & 0.67 \\
\hline Treatment DMMF & $747.62(458.29-1,347.77)$ & I,45I.03 $(4, \mid 87.8 I)$ & 5.95 \\
\hline Surgery DMMF & $0.00(0.00-0.00)$ & $53 \mathrm{I} .94(5,500.4 \mathrm{I})$ & 2.18 \\
\hline Treatment fee & $0.00(0.00-364.00)$ & $1,342.48(5,245.93)$ & 5.51 \\
\hline Non-surgery treatment fee & $0.00(0.00-230.00)$ & $1,065.97(3,503.12)$ & 4.38 \\
\hline Surgery treatment fee & $0.00(0.00-0.00)$ & $276.50(2,697.45)$ & 1.13 \\
\hline Blood and blood products fee & $0.00(0.00-0.00)$ & $104.18(1,507.66)$ & 0.43 \\
\hline Blood fee & $0.00(0.00-0.00)$ & $77.53(1,340.84)$ & 0.32 \\
\hline Albumin fee & $0.00(0.00-0.00)$ & $1.97(53.72)$ & 0.01 \\
\hline Globulin fee & $0.00(0.00-0.00)$ & $24.68(638.31)$ & 010 \\
\hline Other fees & $0.00(0.00-65.00)$ & 77.69 (356.59) & 0.32 \\
\hline Chinese medical treatment & $0.00(0.00-0.00)$ & $45.85(349.48)$ & 0.19 \\
\hline TCM products fee & $0.00(0.00-0.00)$ & 32.21 (123.72) & 0.13 \\
\hline Chinese patent medicine fee & $0.00(0.00-0.00)$ & $17.94(62.03)$ & 0.07 \\
\hline Chinese herbal medicine fee & $0.00(0.00-0.00)$ & 14.27 (77.58) & 0.06 \\
\hline Rehabilitation fee & $0.00(0.00-0.00)$ & $18.36(93.33)$ & 0.08 \\
\hline
\end{tabular}

Note: Items in bold are main cost items.

Abbreviations: TCM, traditional Chinese medicine; DMMF, Disposable medical materials fee.

appeared to be much less than those in the US, this could be explained by the significantly lower average per capita income of Chinese people. In 2016, the average per capita income in the USA was 57,638 USD, while it was only 8,123 USD in China. It was obvious that hospitalization costs unanimously contributed to remarkable expenses for COPD patients in China.
Regarding the formation of hospitalization costs, this study found that Western medicine (pharmaceutical products) fee was the largest part of the total hospitalization costs (45.53\%), followed by diagnosis fee $(27.00 \%)$ and comprehensive medical fee $(12.04 \%)$. These results were consistent with previous findings in China and other countries. A research conducted in 2006 in Beijing city of China

Table 4 Regression analysis for total hospitalization costs (log transformed)

\begin{tabular}{|c|c|c|c|c|}
\hline \multirow[t]{2}{*}{ Factors } & \multicolumn{2}{|l|}{ Univariate analysis } & \multicolumn{2}{|l|}{ Multivariate analysis } \\
\hline & Log transformed $(95 \% \mathrm{CI})$ & $P$-value & Log transformed $(95 \% \mathrm{Cl})$ & P-value \\
\hline Gender & $-0.010(-0.053$ to 0.033$)$ & 0.660 & $0.015(-0.008$ to 0.037$)$ & 0.202 \\
\hline Age & $0.055(0.048-0.438)$ & 0.015 & $-0.022(-0.199$ to 0.008$)$ & 0.071 \\
\hline Reimbursement & $0.043(-0.001$ to 0.072$)$ & 0.057 & $-0.032(-0.046$ to 0.007$)$ & 0.007 \\
\hline Comorbidity & $0.145(0.140-0.262)$ & $<0.001$ & $0.044(0.029-0.093)$ & $<0.001$ \\
\hline Length of stay & $0.829(0.939-0.997)$ & $<0.001$ & $0.738(0.832-0.892)$ & $<0.001$ \\
\hline Surgery & $0.406(0.366-0.448)$ & $<0.001$ & $0.145(0.120-0.170)$ & $<0.001$ \\
\hline Antibiotic use & $0.302(0.25 I-0.333)$ & $<0.001$ & $0.086(0.060-0.107)$ & $<0.001$ \\
\hline Emergency treatment & $0.284(0.366-0.496)$ & $<0.001$ & $0.121(0.147-0.219)$ & $<0.001$ \\
\hline
\end{tabular}


investigated hospitalization costs in patients with AECOPD and found that the highest hospitalization cost was drug cost (71.2\%), followed by laboratory cost (16.7\%). ${ }^{19}$ In a Turkish study conducted in $2014,27.6 \%$ of total hospitalization costs for COPD patients were due to drug use. ${ }^{20}$ In another research in Turkey in 2015, the percentage of drug cost was the highest (53.5\%), followed by bed cost (19.6\%). ${ }^{21} \mathrm{~A}$ similar research in Spain found that drug cost represented $32.2 \%$ of total direct costs for COPD patients. ${ }^{22}$ All these study results indicated the significance of pharmaceutical treatment to the overall medical costs for hospitalized COPD patients.

For patient demographic characteristics, a research in Sweden identified age and gender as factors affecting COPDrelated cost; male and older patients were expected to bear higher costs. ${ }^{23}$ However, no significant effect of gender or age has been observed in this study. This may be due to the inclusion of mainly older patients in this study and, therefore, lack of the data required to demonstrate age significance.

Regarding the effect of reimbursement, this study found that hospitalization costs were significantly $(P<0.05)$ associated with reimbursement according to regression analysis, showing that entitlement to reimbursement could influence medical treatment costs. Moreover, as shown in this study, the costs for patients with or without reimbursement were similar (24,110.84 CNY [3,629.89 USD] vs 25,590.01 CNY [3,852.58 USD]), which could be explained by the reimbursement restrictions set by the social insurance bureau or private insurance companies. ${ }^{24,25}$ The social insurance bureau and private insurance companies in China generally limit the reimbursement categories and set the ceiling for the costs of medical treatment during hospitalization. ${ }^{26}$ Consequently, doctors had to choose less costly treatments to meet the reimbursement requirements.

Regarding the impact of factors related to medical treatment, the regression analysis found that surgery, emergency treatment, comorbidity, antibiotic use, and length of stay were significantly associated with total hospitalization costs. However, among these factors, measures to cut the costs of surgery, emergency treatment, or to reduce comorbidity were neither desirable nor practical for the purpose of hospitalization cost containment. In this study, $11.12 \%$ and $4.53 \%$ patients had surgery and emergency treatment during hospital stay. Patients who had severe dyspnea often needed to take emergency treatment, which would consume more health care resources and need more complex medical therapies, inducing more costs. ${ }^{23,27}$ In addition, according to the GOLD guideline, lung volume reduction surgery (LVRS) and lung transplantation were the two main types of surgeries for
COPD patients, which were effective therapies for severe cases. ${ }^{28}$ Although such kind of surgery was closely related to the severity of COPD and costly for patients resulting in high hospitalization costs, ${ }^{29}$ these measures were crucial for patients' survival and should not be compromised. With regard to comorbidity, in this study, $94.49 \%$ of the COPD patients had concurrent diseases and had higher hospitalization costs. This mirrored the results from another survey study which was conducted in seven countries (Canada, France, Italy, the Netherlands, Spain, UK, and USA). It was found that patients with comorbidity would spend more COPDrelated costs compared with patients without comorbidity. ${ }^{30}$ A research in Italy that included 1,890 COPD patients reported that the presence and the number of comorbidities were significantly linked to the length and costs of hospitalization, especially for patients with cardiovascular disease or diabetes who would have the longest length of stay and highest costs of hospitalization. ${ }^{31}$ In this study, the percentage of patients having comorbidity was very high, which might be due to two reasons. First, the majority of patients included were elderly over 60 years, who were very likely to have other chronic diseases such as cardiovascular disease and diabetes. A previous study found that more than three comorbid disorders were observed in $46 \%$ COPD patients. ${ }^{20}$ Second, as the First Affiliated Hospital of Guangzhou Medical University was ranked the top hospital specializing in COPD, most of the patients who sought help at this hospital were more likely to be seriously ill along with many other comorbidities. Although reducing comorbidity could help reduce hospitalization costs of COPD patients, it was not practical especially when the patients already had more severe cases of COPD during admission. A cross-sectional study in China from 2012 to 2015 found that only 12\% of COPD patients reported previous pulmonary function test, meaning that the majority of COPD patients were not aware of their condition. ${ }^{32}$ To reduce the need for surgery, emergency treatment, and to manage comorbidity, it is important to promote and strengthen early detection of reduced lung function to enable early diagnosis and to prevent disease deterioration at an early stage. This is believed to be of great significance for reducing medical costs for COPD patients in China.

Antibiotics were frequently used in the treatment for COPD patients during hospitalization as infection was one of the main pathological causes for AECOPD. ${ }^{33}$ A randomized trial found that azithromycin (a kind of macrolide antibiotics) could decrease the frequency of exacerbations and improve quality of life for COPD patients. ${ }^{34}$ A retrospective cohort study using data from 410 hospitals in the US indicated that 
adding antibiotics to regimen that already included steroids might have a beneficial effect on the short-term outcome of AECOPD inpatients. ${ }^{35} \mathrm{~A}$ research in Australia found that $85.7 \%$ patients with uncomplicated AECOPD received guideline-discordant antibiotics. ${ }^{36}$ In a Turkish study, $82.8 \%$ of COPD patients of a university hospital used antibiotics therapy. ${ }^{37}$ In this study, $89.91 \%$ patients used antibiotics and antibiotics fee accounted for $38.12 \%$ of Western medicine product fee and $17.3 \%$ of total hospitalization costs, demonstrating the great impact of antibiotic use on hospitalization costs. The main reasons for this phenomenon could be the following. First, because most COPD patients admitted to the First Affiliated Hospital of Guangzhou Medical University had acute exacerbations, according to the GOLD guideline, they would need to use antibiotics to control symptoms rapidly. Second, these patients often suffered from respiratory infections such as pneumonia, bronchiectasis with infection, and pulmonary aspergillosis prompting the need for antibiotic treatment. Third, many Chinese patients today tended to ask doctors to prescribe antibiotics to achieve rapid symptomatic relief without knowing the correct use of antibiotics or ignoring the possible harm of antibiotic abuse. Many doctors, under such pressure, might have a higher tendency to prescribe antibiotics. ${ }^{38,39}$ Therefore, to control possible antibiotic abuse, in addition to implementing hierarchical medical systems, quality control of COPD treatment and patient health education about antibiotic use need to be introduced. For example, in a meta-analysis of double-blind studies about antibiotic treatment of COPD, it was found that short course of antibiotic treatment was as effective as the traditional longer treatment in patients with COPD. ${ }^{40}$

Finally, it is worth noting that rehabilitation costs which covered the cost of rehabilitation assessment and treatment accounted for the smallest proportion $(0.08 \%)$ of total hospitalization costs in this study. It was probably because COPD patients in China paid little attention to rehabilitation. At the same time, it was very difficult for hospitals to promote and charge rehabilitation education and management programs due to price control on reimbursement by government. However, rehabilitation intervention at hospitals has been shown to be beneficial to COPD patients in many ways. ${ }^{41,42}$ For example, a randomized trial in Spain found that COPD patients who joined pulmonary rehabilitation program experienced a significant reduction in exacerbations and achieved health-related quality of life (HRQoL) improvement. ${ }^{43}$ This suggested that rehabilitation program could reduce the probability of hospitalization to a certain extent, thus reducing inpatient costs. The lack of rehabilitation input currently seen in COPD hospitalization in China might be an important area for future improvement. In particular, education about disease management of COPD and other chronic respiratory comorbidities, general health education, and prevention of infectious respiratory diseases would be worth considered during rehabilitation.

This study had several limitations. First, the data analyzed in this study were from one of the top medical institutions specialized in respiratory diseases in China, reflecting the highest level of medical treatment for COPD patients. Most other hospitals in China had less medical capabilities and resources and were subject to varied health policy environment and patient status. Future research that extends to hospitals in different levels and regions is warranted to obtain a more comprehensive understanding about the impacts of hospital levels on hospitalization costs of COPD patients in China. Second, this study only focused on direct medical costs for hospitalized COPD patients but did not evaluate indirect medical costs. As hospitalization may cause considerable indirect medical costs for patients, it demands further investigation on this topic. Third, several background information was unavailable in the dataset such as pulmonary functions, medications for COPD, and previous episode of AECOPD. Fourth, although both surgery and comorbidity are significant contributing factors for hospitalization costs, the types of surgery or comorbidities significantly contributed to the cost need further investigation.

\section{Conclusion}

To control hospitalization costs for COPD patients in China, the significance of comorbidity, length of stay, antibiotic use, surgery, and emergency treatment suggests the importance of controlling the progression of COPD and following clinical guidelines for inpatients. Interventions such as examination of pulmonary function for early detection, quality control of medical treatment, and patient education warrant further investigation.

\section{Data availability}

The datasets of this study are not publicly available because they contain information that may identify patients but are available from the corresponding author on reasonable request.

\section{Acknowledgments}

We acknowledge the support from the Project Hope. We also appreciate the administration help from the First Affiliated Hospital of Guangzhou Medical University. This study was 
supported by the Medical Scientific Research Foundation of Guangdong Province (C2017050). However, the founding sponsors had no role in the design of the study; in the collection, analyses, or interpretation of data; in the writing of the manuscript; and in the decision to publish the results.

\section{Author contributions}

ML and FW are joint first authors. RC and HH conceptualized and designed the study. FW and YY acquired the data. ML, FW, ZL, YZ, COLU, and HH conducted data analysis and interpretation. ML, SC, COLU, and $\mathrm{HH}$ drafted the first version of this manuscript. All the authors reviewed and approved the final version of this manuscript. All authors contributed toward data analysis, drafting and critically revising the paper and agree to be accountable for all aspects of the work.

\section{Disclosure}

The authors report no conflicts of interest in this work.

\section{References}

1. Mathers CD, Loncar D. Projections of global mortality and burden of disease from 2002 to 2030. PLoS Med. 2006;3(11):e442.

2. Hurd S. The impact of COPD on lung health worldwide: epidemiology and incidence. Chest. 2000;117(2 Suppl):1S-4S.

3. Einarson TR, Bereza BG, Nielsen TA, van Laer J, Hemels ME. Systematic review of models used in economic analyses in moderate-to-severe asthma and COPD. J Med Econ. 2016;19(4):319-355.

4. Mulpuru S, Mckay J, Ronksley PE, Thavorn K, Kobewka DM, Forster AJ. Factors contributing to high-cost hospital care for patients with COPD. Int J Chron Obstruct Pulmon Dis. 2017;12:989-995.

5. Dalal AA, Christensen L, Liu F, Riedel AA. Direct costs of chronic obstructive pulmonary disease among managed care patients. Int $J$ Chron Obstruct Pulmon Dis. 2010;5:341-349.

6. Chiang $\mathrm{CH}$. Cost analysis of chronic obstructive pulmonary disease in a tertiary care setting in Taiwan. Respirology. 2008;13(5):689-694.

7. Hutchinson A, Brand C, Irving L, Roberts C, Thompson P, Campbell D. Acute care costs of patients admitted for management of chronic obstructive pulmonary disease exacerbations: contribution of disease severity, infection and chronic heart failure. Intern Med J. 2010;40(5):364-371.

8. Maleki-Yazdi MR, Kelly SM, Lam SY, Marin M, Barbeau M, Walker V. The burden of illness in patients with moderate to severe chronic obstructive pulmonary disease in Canada. Can Respir J. 2012;19(5):319-324.

9. Fang X, Wang X, Bai C. COPD in China: the burden and importance of proper management. Chest. 2011;139(4):920-929.

10. Wang C, Xu J, Yang L, et al; China Pulmonary Health Study Group. Prevalence and risk factors of chronic obstructive pulmonary disease in China (the China Pulmonary Health $[\mathrm{CPH}]$ study): a national crosssectional study. Lancet. 2018;391(10131):1706-1717.

11. Chen X, Wang N, Chen Y, Xiao T, Fu C, Xu B. Costs of chronic obstructive pulmonary disease in urban areas of China: a cross-sectional study in four cities. Int J Chron Obstruct Pulmon Dis. 2016;11:2625-2632.

12. Cai B, Cai S, Chen R, Cui L, Feng Y, Gu T, Shi Y. Expert consensus on acute exacerbation of chronic obstructive pulmonary disease in the People's Republic of China. Int J Chron Obstruct Pulmon Dis. 2014;9: 381-395.

13. Liu H, Wang N, Chen W, et al. Hospitalization Trends in Adult Patients with COPD and Other Respiratory Diseases in Northeast China from 2005 to 2015. Biomed Res Int. 2018;2018:1-7.
14. Zhu B, Wang Y, Ming J, Chen W, Zhang L. Disease burden of COPD in China: a systematic review. Int J Chron Obstruct Pulmon Dis. 2018;13: 1353-1364.

15. From the Global Strategy for the Diagnosis, Management and Prevention of COPD [homepage on the Internet]. Global Initiative for Chronic Obstructive Lung Disease. Available from: http://goldcopd.org/ gold-2017-global-strategy-diagnosis-management-prevention-copd/. Accessed May 30, 2017.

16. Chronic Obstructive Pulmonary Disease Group, Respiratory Disease Branch, Chinese Medical Association. Chinese Guidelines for the Diagnosis and Treatment of Chronic Obstructive Pulmonary Diseases (Revised 2013). Chin J Med Sci. 2014;6(2):67-80. Chinese.

17. Perera PN, Armstrong EP, Sherrill DL, Skrepnek GH. Acute exacerbations of COPD in the United States: inpatient burden and predictors of costs and mortality. COPD. 2012;9(2):131-141.

18. Pasquale MK, Sun SX, Song F, Hartnett HJ, Stemkowski SA. Impact of exacerbations on health care cost and resource utilization in chronic obstructive pulmonary disease patients with chronic bronchitis from a predominantly Medicare population. Int J Chron Obstruct Pulmon Dis. 2012;7:757-764.

19. Chen YH, Yao WZ, Cai BQ, et al. Economic analysis in admitted patients with acute exacerbation of chronic obstructive pulmonary disease. Chin Med J. 2008;121(7):587-591

20. Deniz S, Şengül A, Aydemir Y, Çeldir Emre J, Özhan MH. Clinical factors and comorbidities affecting the cost of hospital-treated COPD. Int J Chron Obstruct Pulmon Dis. 2016;11:3023-3030.

21. Ozkaya S, Findik S, Atici AG. The costs of hospitalization in patients with acute exacerbation of chronic obstructive pulmonary disease. Clinicoecon Outcomes Res. 2011;3:15-18.

22. Miravitlles M, Murio C, Guerrero T, Gisbert R, DAFNE Study Group. Decisiones sobre Antibioticoterapia y Farmacoeconomía en la EPOC. Pharmacoeconomic evaluation of acute exacerbations of chronic bronchitis and COPD. Chest. 2002;121(5):1449-1455.

23. Gerdtham UG, Andersson LF, Ericsson A, et al. Factors affecting chronic obstructive pulmonary disease (COPD)-related costs: a multivariate analysis of a Swedish COPD cohort. Eur J Health Econ. 2009; 10(2):217-226.

24. Filipski MJ, Zhang Y, Chen KZ. Making health insurance pro-poor: evidence from a household panel in rural China. BMC Health Serv Res. 2015;15(1):210.

25. Zhang C, Lei X, Strauss J, Zhao Y. Health Insurance and Health Care among the Mid-Aged and Older Chinese: Evidence from the National Baseline Survey of CHARLS. Health Econ. 2017;26(4):431-449.

26. Hou JW, Li K. The aging of the Chinese population and the cost of health care. Soc Sci J. 2011;48(3):514-526.

27. Örnek T, Tor M, Altın R, et al. Clinical factors affecting the direct cost of patients hospitalized with acute exacerbation of chronic obstructive pulmonary disease. Int J Med Sci. 2012;9(4):285-290.

28. Marchetti N, Criner GJ, Albert RK. Preventing acute exacerbations and hospital admissions in COPD. Chest. 2013;143(5):1444-1454.

29. Elpern EH, Behner KG, Klontz B, Warren WH, Szidon JP, Kesten S. Lung volume reduction surgery: an analysis of hospital costs. Chest. 1998;113(4):896-899.

30. Wouters EF. Economic analysis of the Confronting COPD survey: an overview of results. Respir Med. 2003;97(Suppl C):S3-S14.

31. Terzano C, Colamesta V, Unim B, et al. Chronic obstructive pulmonary disease (COPD) exacerbation: impact of comorbidities on length and costs during hospitalization. Eur Rev Med Pharmacol Sci. 2017; 21(16):3680-3689.

32. Wang C, Xu J, Yang L, et al; China Pulmonary Health Study Group. Prevalence and risk factors of chronic obstructive pulmonary disease in China (the China Pulmonary Health [CPH] study): a national crosssectional study. Lancet. 2018;391(10131):1706-1717.

33. Celli BR, Barnes PJ. Exacerbations of chronic obstructive pulmonary disease. Eur Respir J. 2007;29(6):1224-1238.

34. Albert RK, Connett J, Bailey WC, et al. Azithromycin for prevention of exacerbations of COPD. N Engl J Med. 2011;365(8):689-698. 
35. Stefan MS, Rothberg MB, Shieh MS, Pekow PS, Lindenauer PK. Association between antibiotic treatment and outcomes in patients hospitalized with acute exacerbation of COPD treated with systemic steroids. Chest. 2013;143(1):82-90.

36. Fanning M, Mckean M, Seymour K, Pillans P, Scott I. Adherence to guideline-based antibiotic treatment for acute exacerbations of chronic obstructive pulmonary disease in an Australian tertiary hospital. Intern Med J. 2014;44(9):903-910.

37. Y1ldırım F, Türk M, Öztürk C. Costs of the Patients Hospitalized with Acute Exacerbations of Chronic Obstructive Pulmonary Disease in a University Hospital. Eurasian J Pulmonol. 2015;17(3):171-175.

38. Currie J, Lin W, Zhang W. Patient knowledge and antibiotic abuse: Evidence from an audit study in China. J Health Econ. 2011;30(5): 933-949.
39. Currie J, Lin W, Meng J. Addressing antibiotic abuse in China: An experimental audit study. J Dev Econ. 2014;110:39-51.

40. El Moussaoui R, Roede BM, Speelman P, Bresser P, Prins JM, Bossuyt PM. Short-course antibiotic treatment in acute exacerbations of chronic bronchitis and COPD: a meta-analysis of double-blind studies. Thorax. 2008;63(5):415-422.

41. Hui KP, Hewitt AB. A simple pulmonary rehabilitation program improves health outcomes and reduces hospital utilization in patients with COPD. Chest. 2003;124(1):94-97.

42. Seemungal TA, Hurst JR, Wedzicha JA. Exacerbation rate, health status and mortality in COPD - a review of potential interventions. Int J Chron Obstruct Pulmon Dis. 2009;4:203-223.

43. Güell R, Casan P, Belda J, et al. Long-term effects of outpatient rehabilitation of COPD: A randomized trial. Chest. 2000;117(4):976-983.

International Journal of COPD

\section{Publish your work in this journal}

The International Journal of COPD is an international, peer-reviewed journal of therapeutics and pharmacology focusing on concise rapid reporting of clinical studies and reviews in COPD. Special focus is given to the pathophysiological processes underlying the disease, intervention programs, patient focused education, and self management protocols.

\section{Dovepress}

This journal is indexed on PubMed Central, MedLine and CAS. The manuscript management system is completely online and includes a very quick and fair peer-review system, which is all easy to use. Visit http://www.dovepress.com/testimonials.php to read real quotes from published authors.

Submit your manuscript here: http://www.dovepress.com/international-journal-of-chronic-obstructive-pulmonary-disease-journal 